\title{
Insights into North Pacific right whale Eubalaena japonica habitat from historic whaling records
}

\author{
Edward James Gregr*
}

SciTech Environmental Consulting, 2136 Napier Street, Vancouver, British Columbia V5L 2N9, Canada

\begin{abstract}
Whaling records from the mid-1800s provide the largest set of observations with which to conduct a basin-scale analysis of potential North Pacific right whale Eubalaena japonica habitat. Since these data lack the concurrent oceanographic data necessary to investigate the species' habitat characteristics I used ocean climate from a 20th century circulation model to create a suitable set of habitat predictors. My goals were to (1) identify regions of suitable habitat and (2) investigate the processes underlying the species-habitat relationship by (3) examining model performance at different spatial and temporal scales. The results show 2 non-overlapping habitat regions in the subarctic North Pacific, supporting the notion of 2 distinct subpopulations. The analysis also implicates surface temperature and temperature variability as strong indicators of potential right whale habitat. Tests of model performance at different scales strongly suggest that at the basin-scale, right whales use regions of cold water with low inter-annual variability and high within-season variability (i.e. areas where high frontal activity occurs predictably from year to year). The significance of these indicators decreased at the regional scale emphasising the coupling of scale and process, and thus the need for different predictors at different scales. Comparisons of models built using different subsets of the dependent data showed how hypotheses can be tested and potential biases in observational data can be explored. Analyses of rare species' habitat such as this can provide guidance for more directed survey efforts and help identify areas and processes of potential biological importance.
\end{abstract}

KEY WORDS: Habitat suitability model $\cdot$ Pelagic habitat $\cdot$ Concentration features $\cdot$ Critical habitat Habitat processes · Ecological niche $\cdot$ Presence-only · Maximum entropy

Resale or republication not permitted without written consent of the publisher

\section{INTRODUCTION}

The right whale was the first species of large whale to be driven to near extinction by 19th century whaling, as whalers in sailing ships scoured the entire North Pacific in search of ever-dwindling prey. The eastern subpopulation, estimated in the dozens (Wade et al. 2010), remains at critically low levels, while the western subpopulation, numbering in the hundreds (Brownell et al. 2001), appears relatively better off.

Historically, North Pacific right whales Eubalaena japonica are believed to have ranged across the entire North Pacific (Scarff 1986, 1991, Brownell et al. 2001, Clapham et al. 2004), with concentrations in the Gulf of Alaska (GOA), the southeastern Bering Sea (SEBS), the Sea of Okhotsk, the Kuril and Kamchatka coasts, and the Sea of Japan (Fig. 1). They were also found in oceanic waters across much of the North Pacific (Braham \& Rice 1984, Scarff 1991, Clapham et al. 2004). The last known large concentrations in the eastern North Pacific occurred in the northern Gulf of Alaska and on the SEBS shelf and were the focus of illegal Soviet whaling between 1963 and 1967 (Brownell et al. 2001). The few sightings of right whales in the eastern North Pacific since the 1980s have generally been concentrated in Alaskan waters, where considerable survey effort 


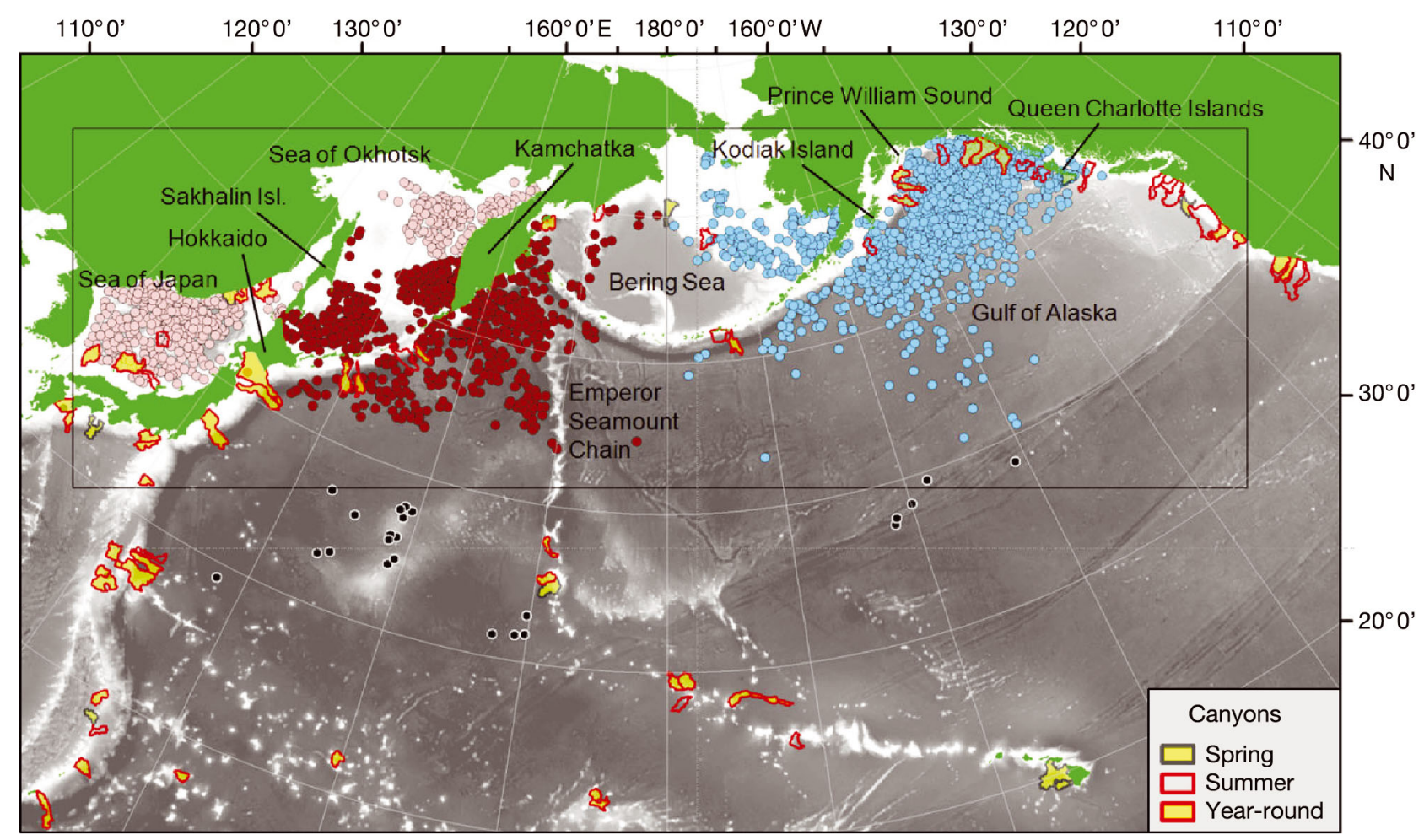

Fig. 1. Extent of study area showing the historic whaling data compiled by Townsend (1935) and digitised by the Wildlife Conservation Society (2004). The data were divided into eastern (blue) and western (red and pink) subpopulations of Eubalaena japonica based on $180^{\circ}$ longitude for analysis. Black dots south of $40^{\circ} \mathrm{N}$ were excluded because foraging is believed to be unlikely at these latitudes. The black frame shows the reduced study area extent used for regional models. Pink dots in the western subpopulation represent kills that may not have been foraging right whales (see 'Materials and methods'); their potential to bias model predictions was tested. Predicted upwelling canyons are shown based on the interaction between canyon size $\left(>1500 \mathrm{~m}^{2}\right)$, vertical rise $(>1000 \mathrm{~m})$, aspect and seasonal current direction (author's unpubl. data)

has been applied (Shelden et al. 2005). Contemporary sightings in the western North Pacific continue to be made in the historic areas of use (Brownell et al. 2001).

Like most baleen whales, right whales tend to occupy high-latitude feeding grounds from spring to autumn, moving to lower latitudes in winter, presumably to calve. They are believed to forage almost exclusively on large-bodied copepods (Omura et al. 1969, Gregr \& Coyle 2009). Predictive models of potential habitat, with an emphasis on the underlying processes, would greatly improve our understanding of how this species uses its oceanic environment. This would support conservation efforts in a number of ways, such as improving at-sea encounter rates, thereby increasing the effectiveness of field surveys. The predictions could also serve to assist with management decisions, such as assessing potential risks to the species and improving descriptions of critical habitat.

However, habitat studies of rare species such as the North Pacific right whale in a space as large as the North Pacific Ocean face significant chal- lenges. Developing species-habitat relationships relies on correlations between a sizeable sample of species occurrences and environmental observations (Guisan \& Zimmermann 2000). Not only are there few contemporary right whale sightings, but observations of the physical marine environment, particularly on the high seas, are extremely patchy in time and space (Munk 2000). I overcame the first problem by using historic whaling records and the second problem by using the output from a general circulation model (GCM) of the North Pacific. GCMs, while still striving to capture finescale detail, do well at describing average ocean conditions (Gregr \& Coyle 2009).

In this analysis, I focused on the basin scale, where right whale movements between feeding and wintering grounds and between different feeding areas are likely mediated by seasonal changes in foraging opportunities (Gregr \& Coyle 2009). Kenney et al. (2001) proposed that movements at this scale are related to aspects of topography, ocean currents and acoustics. I therefore assumed that individuals use 
oceanographic cues to find patches of copepods suitable for foraging (Kenney et al. 2001, Baumgartner et al. 2007, Gregr \& Coyle 2009).

Since both the production and retention of plankton are forced by dynamics at multiple scales (Bakun 1996), I explored the effects of temporal resolution and study area extents - the 2 components of scale - on the relationship between right whale observations and the physical predictor variables. I used a presence-only approach to relate the historic whaling data and the predictor variables, developed annual and seasonal models to explore the effect of seasonality, and tested the effect of model design (data selection and spatial extents) on model performance.

\section{MATERIALS AND METHODS}

I used the Wildlife Conservation Society's (2004) digitisation of the Townsend (1935) catch data as my dependent data. These data include the locations of whales killed during the peak of right whale exploitation - a brief $10 \mathrm{yr}$ period beginning about 1840 (Josephson et al. 2008a). I constrained the study to the subarctic North Pacific, generally considered to be north of $40^{\circ} \mathrm{N}$ latitude (Uda 1963). I included the records south of $40^{\circ} \mathrm{N}$ in the Sea of Japan for completeness. Following Brownell et al. (2001), I divided the data into eastern and western stocks based on an assumed boundary at $180^{\circ}$ longitude. For the seasonal models, I defined spring and summer according to peak biomass and surface residencies of key prey species, summarised by Gregr \& Coyle (2009). Spring (April to June) overlapped with the peak surface residency time of adult large-bodied copepods, while summer (July to September) overlapped with the peak abundance of the smaller shelf-dwelling copepod species. I omitted the remaining 6 months (October to March) as very few whaling records exist for those months.

I based my preliminary selection of predictor variables on a combination of ecological understanding and data availability. These data included static geographic variables defined from bathymetry (depth) and dynamic ocean climate variables (e.g. temperature) scaled to match the seasonal partitioning of the right whale data. The geographic variables were derived from the ETOPO1 global elevation data set (Amante \& Eakins 2009) and included depth (z), slope (the rate of change of depth, $z^{\prime}$ ), complexity (the rate of change of slope, $z^{\prime \prime}$ ) and distance to the $200 \mathrm{~m}$ contour $\left(d_{200}\right)$.
I characterised ocean climate using the output from a GCM for the North Pacific (Wang \& Chao 2004). Results were available for the second half of the 20th century, with high temporal resolution, on a halfdegree longitude-latitude grid. I assumed that at the basin scale, a long-term 20th century climatology (i.e. a map of mean conditions) reasonably represented the relative seasonal ocean conditions that existed at this spatial resolution during the early, intense phase of the right whale fishery (1840s). I also assumed the GCM output produced a reasonable measure of the true relative differences in late 20th century ocean climate.

From the GCM, I obtained mean monthly wind speed, temperature and salinity (both at 1, 10, 50 and $150 \mathrm{~m}$, and bottom) and current speed (surface, 50 and $150 \mathrm{~m}$, and bottom) for all months from 1950 to 2001. I created $50 \mathrm{yr}$ annual and seasonal (spring, summer) climatologies for each variable, with the seasonal climatologies based on the mean of all monthly values in each season. From these climatologies, I calculated 2 difference variables (surface $-50 \mathrm{~m}$ and surface $-150 \mathrm{~m}$ ) for temperature, salinity and currents to represent the potential influence of the surface mixed layer and the permanent halocline, respectively.

I defined a dynamic (seasonal) geographic variable, distance to upwelling canyons $\left(d_{\mathrm{uw}}\right.$ Fig. 1$)$. This variable represents the distance to canyons capable of generating upwelling via bathymetric steering. Upwelling canyons were defined as those whose aspect opposed, with a $45^{\circ}$ tolerance, the seasonal current at $150 \mathrm{~m}$ depth (author's unpubl. data).

Finally, I defined 2 measures of variability to capture intra- and inter-annual variability. I defined the mean seasonal variability (sv) as a measure of the average long-term variability of temperature or salinity within a season (Eq. 1). I defined the interannual variability (av) as a measure of how the mean of a variable changes from year to year (Eq. 2).

$$
\begin{gathered}
\mathrm{sv}=\frac{\sum_{y=1}^{50}\left(\bar{t}_{Y}-\bar{T}\right)^{2}}{50} \text { where } \bar{T}=\frac{\sum_{y=1}^{50} \sum_{m=1}^{3} t_{m y}}{150} \\
\mathrm{av}=\frac{\sum_{y=1}^{50} \sum_{m=1}^{3}\left(t_{m y}-\overline{t_{Y}}\right)^{2}}{150}
\end{gathered}
$$

The equations show the calculation for temperature $(t) ; y$ indicates the years available and $m$ the months within the seasons. I calculated these predictors for temperature and salinity, for both seasons (spring, summer), and for both surface and bottom depths. These variables were, by definition, only relevant for the seasonal models. 
In all, I considered a total of 34 predictor variables (5 geographic and 29 oceanographic), most of which had both annual and seasonal forms. Exceptions included the 8 variability measures which applied only to the seasonal models, and all but one (distance to upwelling canyons) of the geographic variables. I projected all data to a Lambers Conic equi-distance projection centred on $180^{\circ} \mathrm{N}$. Data were managed using ArcGIS 9.3 (ESRI 2008).

I scaled the study in consideration of the independent data used and the temporal mismatch between these and the dependent data. The half-degree resolution of the CGM corresponded to a projected grid of $50 \times 50 \mathrm{~km}^{2}$ cells. While this spatial resolution would support a monthly temporal resolution, I used seasonal climatologies to reduce potential differences between the dependent and predictor data sets. The long-term (i.e. $50 \mathrm{yr}$ ) climatology removed much of the inter-annual variability (e.g. El Niño, Pacific Decadal Oscillation), while seasonal averaging removed within-season variability, leaving only the strongest long-term seasonal signals in the data. Spatially, the $50 \times 50 \mathrm{~km}^{2}$ resolution removed local, high-frequency patterns, such as fronts and eddies, leaving behind basin-scale signals well suited to the defined temporal scale. This reduction of the ocean climate to the strongest seasonal signals helped overcome any climate differences between the 2 eras.

A challenge to predicting habitat using any opportunistically collected data set, such as historic whaling records, is a lack of true absence data. Such analyses require either presence-only methods, or a means of generating pseudo-absences. In a review of how 11 different habitat modelling methods performed in handling presence-only data, Elith et al. (2006) drew 2 important conclusions. First, presenceonly data can reliably be used to model species distributions. Second, new machine-learning methods (essentially computer-based pattern detection algorithms) outperformed both established presence-only methods and the regression-based, presenceabsence approaches (i.e. generalised linear and additive models with pseudo-absence data) based on several criteria (Elith et al. 2006). This and other comparisons of presence-only methods (e.g. Wisz et al. 2008, Tittensor et al. 2009) found that the maximum entropy method (MaxEnt; Phillips et al. 2006) regularly performed better than other approaches. I therefore used MaxEnt (Version 3.3.1) to build the predictive models for the present analysis.

The MaxEnt tool iteratively searches for the multivariate distribution that is closest to uniform, subject to the constraint that the expected value of each pre- dictor variable (or its transform and/or interactions) matches the average associated with the species observations (Phillips et al. 2006). Essentially, it minimises the difference between 2 probability densities (i.e. observed and background) defined in feature space (Elith et al. 2011; for more details see Phillips et al. 2006, Dudík et al. 2007, Phillips \& Dudík 2008).

MaxEnt uses a number of variable formulations (called features) to fit the model. Features include forms normally associated with envelope models, such as threshold and hinge features (step- and piece-wise functions, respectively), and regressionlike forms, such as linear, quadratic and product terms (Phillips \& Dudík 2008). To reduce the potential for over-fitting, MaxEnt provides a variable (regularisation) to reduce the precision of the fit required from each variable. Higher regularisation gives a less precise fit to the constraints.

I elected not to compare a variety of modelling methods because my focus here was on the exploration of the spatio-temporal scaling of the data. While a comparison of methods would be warranted prior to adopting any such results for management, it would unnecessarily complicate the results presented here without significantly influencing the conclusions.

I began by developing annual models to explore differences between the western and eastern subpopulations of North Pacific right whales. I used these annual models to examine how the spatial extents of both the dependent and the predictor data influenced model performance. I then developed seasonal (spring, summer) models for each subpopulation to evaluate how the performance of the predictor variables changed at different temporal scales. Finally, I investigated how the predictions for the western subpopulation responded to the removal of potentially biasing records (i.e. right whale records from the northern Sea of Okhotsk likely represent bowhead whales [Josephson et al. 2008b], while it is unclear whether the Sea of Japan represents a foraging ground, or simply a migratory corridor [Brownell et al. 2001]). In total, I built 8 annual and 14 seasonal models by systematically modifying the temporal resolution and spatial extents of the data used.

I compared model performance using the regularised gain and the AUC (area under the receiveroperating characteristic curve; Fielding \& Bell 1997) statistics reported by MaxEnt. Gain is related to deviance and measures goodness-of-fit using the average log probability of the presence samples. It starts at 0 and increases towards an asymptote as the model is fit, effectively measuring how closely the 
resulting model fits the presence samples. The AUC statistic, while sensitive to the size of the study area and other factors (Lobo et al. 2008), nevertheless provides an acceptable measure of model performance, particularly when comparing relative model performance (Elith \& Graham 2009).

While models built to predict species' distributions (such as many contemporary terrestrial models) commonly use data-splitting to evaluate predictive power (Rykiel 1996, Guisan \& Zimmermann 2000), the appropriate evaluation approach depends on the objectives (Rykiel 1996). My objective was not to predict the potential distribution of right whales, since for severely reduced populations such models willat best - predict the ecological niche of the species, not its realised distribution. Rather, I was interested in comparing models across different scales of analysis and drawing inferences about the underlying processes. Given that model comparison - not absolute model performance - is the objective, I argue that comparing models built with all available dependent data, particularly in cases such as this where the observations are well distributed throughout the study area, is appropriate. I therefore used all the dependent data (constrained by study extents and season) to fit all models and calculate performance statistics.

To test whether changes in model performance were due to changes in spatial and temporal scale rather than just the corresponding change in sample size, I applied a null model test to each such comparison. I calculated bootstrapped confidence intervals for the AUC and gain statistics by drawing 5000 random samples, the same size as the subset data, from the larger data set. I then compared the gain and AUC of the subset models to these test distributions and concluded that changes in model performance were not simply due to a reduced sample size if the statistics for the subset models fell outside the $95 \%$ bootstrapped confidence interval.

I began the variable selection process by summarising the full set of predictor variables in a correlation matrix. To improve the independence of the predictor variables, I dropped the most cross-correlated variables (i.e. those correlated at $\geq 0.80$ with most other variables). I used the full suite of uncorrelated predictor variables to develop an annual model for the entire North Pacific study area using all the observational data. I built 2, basin-extent annual subpopulation models by recalibrating the full annual model with the dependent data divided into western and eastern subpopulations to test whether focusing on subpopulations improved model performance. I com- pared the performance of the 2 subpopulation models to the full annual model using the null model test.

I then created regional subpopulation models by reducing the spatial extents of the annual subpopulation models to their respective regions (black frame, with subpopulations separated by $180^{\circ} ;$ Fig. 1 ). I used these models to explore the effects of reduced spatial extents. Finally, I reduced the complexity of the basin-extent subpopulation models by removing predictor variables that cumulatively contributed $<10 \%$ to the model prediction across the 5 annual model variants. This resulted in the final set of basin-extent, reduced, annual subpopulation models and associated predictor variables. These were compared to the final (8th) annual model built with all the observational data and the reduced set of predictor variables.

At the seasonal resolution, I partitioned the observational data into spring and summer and used seasonal climatologies as the predictor variables. I built 3 variants of the seasonal subpopulation models (yielding a total of 12 models); the data reduction experiment yielded an additional 2 models for the western subpopulation. For the first seasonal subpopulation models I used only the seasonal variants of the final annual predictor variables. These models allowed me to test whether changing only the temporal resolution improved model performance. I then built additional models by first adding the 8 variability measures and then removing the most redundant predictor variables based on MaxEnt's jackknife test of variable importance. The jackknife test calculates the drop in performance as each variable is omitted from the fully specified model. The variable resulting in the lowest drop in gain can be considered the most redundant as its power to fit to the data is compensated for by the remaining variables. Following Yost et al. (2008), I ran the jackknife test using 10 random partitions of the dependent data (70\% training, 30\% testing), with randomised selection of background cells (i.e. predictor data). I removed the most redundant variable based on the mean gain of the 10 model runs. I repeated the process, removing 1 variable at a time, until the gain fell outside the $95 \%$ confidence interval of the mean gain of the fully specified model. Applying this to each of the seasonal subpopulation models gave the final set of reduced seasonal subpopulation models. I presented all model predictions using the default logistic distribution, which can be interpreted as relative suitability (Dudík et al. 2007).

I used the basin-scale extents for the seasonal models because this resolution was more appropriate given the nature of the data and scale of analysis (see 
'Discussion'). I used this scale to also test the effect of removing potentially biasing data from the western subpopulation model.

I investigated the characteristics of the predicted habitats by examining how the ocean climate variables differed between locations where the animals were killed and the background ocean climate using a re-scaled histogram, generated with the S-Plus density function (S-Plus 2007). To focus on areas where right whales were more common, I restricted this analysis to cells with near-surface temperatures $<20^{\circ} \mathrm{C}$. I tested to see if the distributions of predictor variables were significantly different using the Kolmogorov-Smirnov test. This analysis of key predictor variable distributions contributed to insights about the possible processes represented by the predictive models.

\section{RESULTS}

Out of a total of 2001 right whale Eubalaena japonica kills in the entire North Pacific, I removed 51 that were south of $40^{\circ} \mathrm{N}$ in the main basin (retaining those south of $40^{\circ} \mathrm{N}$ in the Sea of Japan). I also removed 42 records (12 in the west and 30 in the east) that occurred on land cells (due to the spatial resolution of analysis) and an additional 32 records (6 in the west and 26 in the east) that occurred in winter. This left 1876 records for the annual model, with 857 in spring and 1019 in summer. The 1876 annual records occurred in 1345 grid cells. This ratio of presence cells to observations $(\sim 70 \%)$ was fairly consistent across the different models.

In the present study, the default MaxEnt parameters led to considerable overfitting of the models (e.g. Fig. 2a). Excluding MaxEnt's hinge and threshold features eliminated such 'skyline' plots (Fig. 2b) and reduced the number of parameters used to fit the models by more than half. I therefore limited all models to linear and quadratic features, with interactions, leaving the remaining MaxEnt parameters at their default settings.

Of the 26 variables considered for the annual models, I removed slope, and temperature and salinity at 3 depths (surface, $50 \mathrm{~m}$ and $150 \mathrm{~m}$ ) because their influence was retained in the model by other, correlated

$(\geq 0.8)$ predictors. I used the remaining 19 variables (Table 1) to build 3 basin-extent models with different sets of observational data and 2 regional (reduced extent) models for the western and eastern subpopulations. The subpopulation models (gain = 1.964 and 2.148; $\mathrm{AUC}=0.967$ and 0.977, for west and east, respectively; Table 2) outperformed the full annual model (gain $=1.317$; AUC $=0.937$ ), suggesting that the observational data are better fit when separated. The $95 \%$ confidence intervals (CI) for the null model test (1.4886 to 1.4863 and 1.4795 to 1.4817, for west and east, respectively; Table 3) show only marginal increases over the full annual model, confirming that the improved performance of the subpopulation models was largely due to the separation of observations into subpopulation models. Rescaling the subpopulation models to the regional scale led to a large decrease in model performance (gain $=0.647$ and 1.264; $\mathrm{AUC}=0.817$ and 0.901, for west and east, respectively), particularly in the west.

Based on the importance of individual predictor variables across these 5 models, I removed 7 predictor variables that had a summed, total contribution of $<10 \%$ (Table 1). This manipulation defined the final set of 12 variables (unshaded; Table 1) used to build the reduced annual models. The habitat predictions from the annual subpopulation models were mutually exclusive and appeared to refine the predictions made by the full annual model (Fig. 3). The performance of the reduced basin-extent models was only marginally lower than the fully specified models (Table 2).

The difference between the full and subpopulation annual model predictions can be attributed entirely

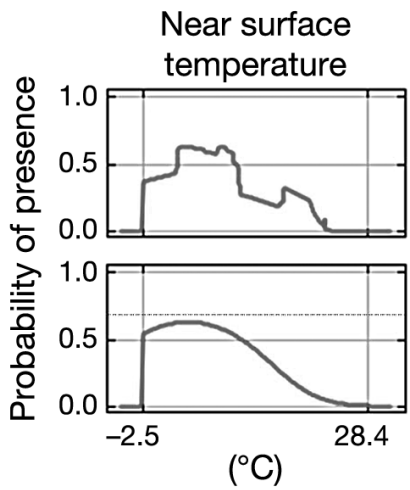

Fig. 2. Examples of MaxEnt models for the fit of 3 response variables using: (a) default regularisation and default feature selection and (b) all but 2 fitting features (threshold and hinge), as done in the present analysis. The default settings (a) produced 'skyline' plots strongly indicative of overfitting, while removing the threshold and hinge features (b) produced more ecologically interpretable relationships. See 'Results' for details 
Table 1. Independent variables used in the development of predictive models of historic North Pacific right whale Eubalaena japonica habitat and their percent contribution to each of the 8 annual and 14 seasonal models developed (see Table 2). Annual models were developed for 2 spatial extents (basin and regional) using 3 subsets of dependent data (all, western (W) and eastern (E) subpopulations). Seasonal models were built for spring (Spr) and summer (Sum). Variables selected for the final annual models ( $\mathrm{n}=12$ ) based on a 2-step variable removal process (see 'Materials and methods' for details) have their abbreviations shown in bold print. Percent contributions to overall model performance are shown for the variables retained in each model; the top 5 contributing variables are shaded according to rank (red, orange, yellow, teal and blue corresponding to ranks 1 through 5, respectively). Variables with grey-shaded annual contributions were removed from the annual models based on a summed contribution of $<10 \%$. Gaps represent variables not used

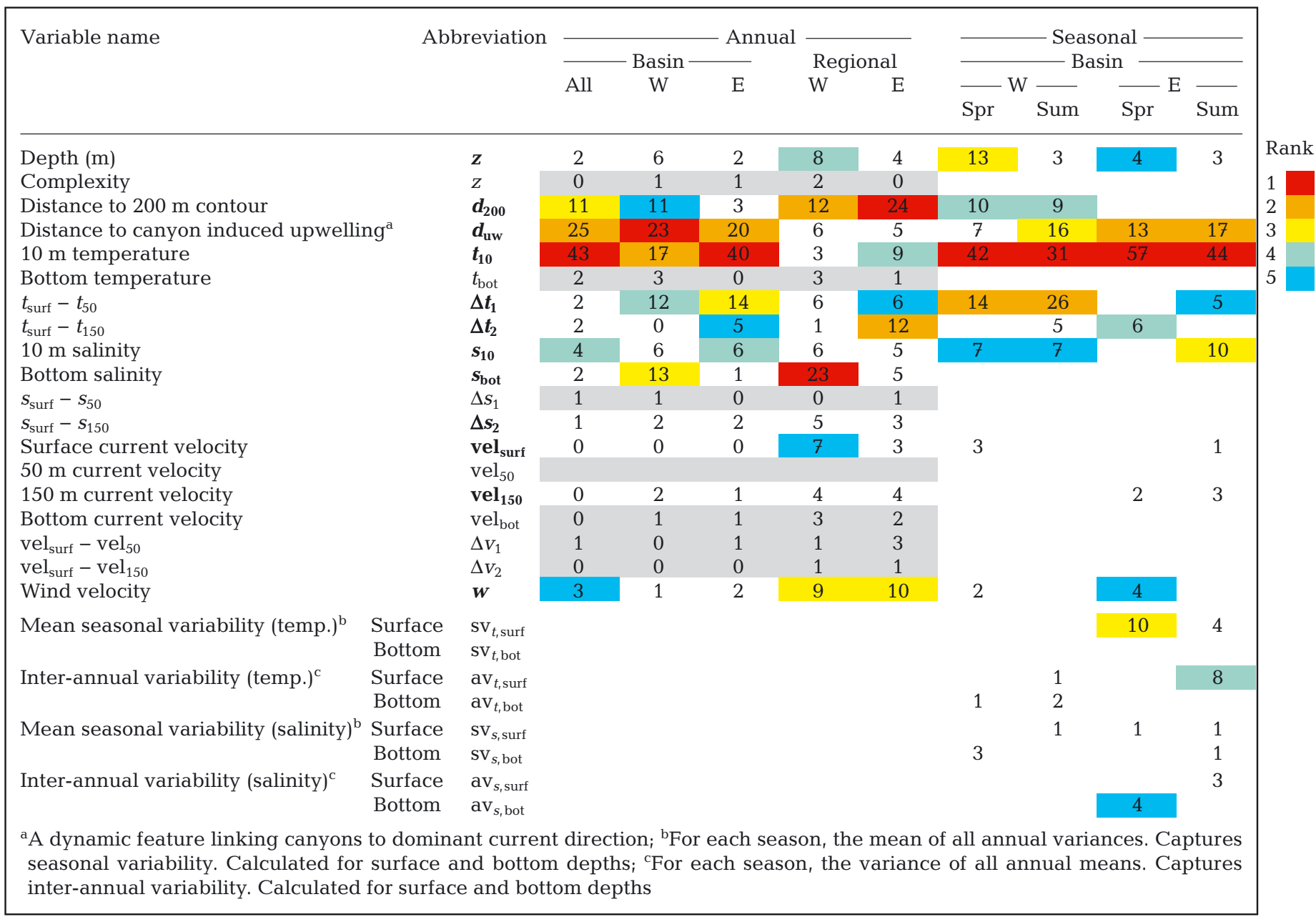

to ocean climate, as predictions generated with only the geographic data (not shown) were spread across the shelf and slope of the entire study area. The largest contribution to all the annual, basin-scale models was from near-surface temperature $\left(t_{10}\right)$ and distance to upwelling canyons $\left(d_{\mathrm{uw}}\right)$ (Table 1$)$. The major contributing variables to the regional annual subpopulation models differed from the basin-extent models and between subpopulations (Table 1). Bottom salinity $\left(s_{\text {bot }}\right)$ and distance to the $200 \mathrm{~m}$ contour $\left(d_{200}\right)$ were the largest contributors to the western and eastern regional subpopulation models, respectively.

The seasonal models (using the seasonal variants of the 12 predictor variables retained from the annual models) showed large improvements in model per- formance (Table 2). Restricting the dependent data for the western subpopulation by removing the potentially biased observations further improved that model's performance (Table 2), and the null model tests confirmed that these improvements were significantly more than expected through only reducing the sample size (Table 3). I therefore used the reduced set of observations (W-s in Table 2) in the subsequent western subpopulation models.

The addition of the seasonal variability predictors increased the number of predictors to 20 and further improved the performance of the seasonal models for both subpopulations (Table 2). The subsequent removal of variables based on redundancy left 10 variables in both western models and 9 and 12 vari- 


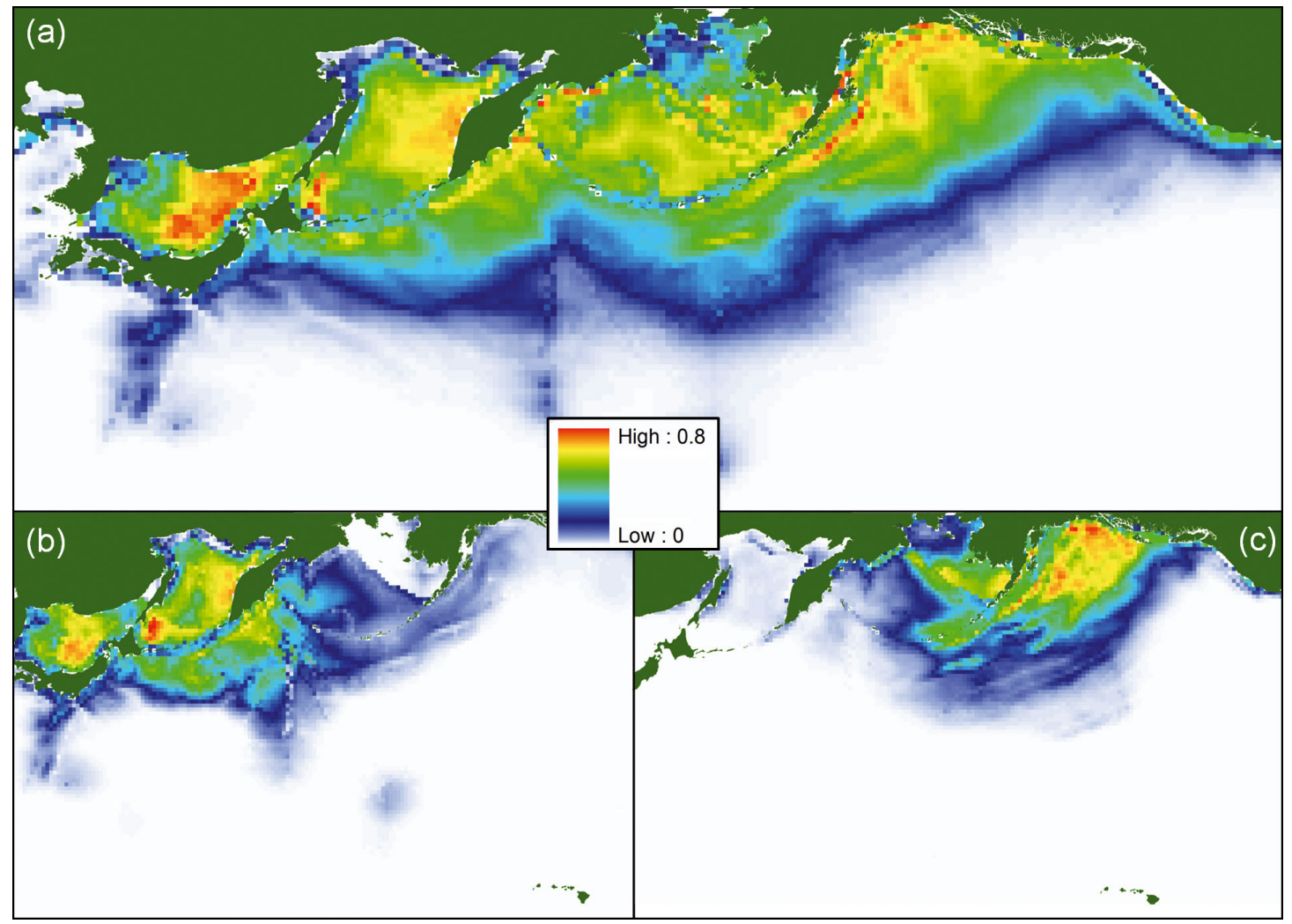

Fig. 3. Eubalaena japonica. Annual basin-extent model predictions based on the reduced set of 12 predictor variables using (a) all dependent data, and the (b) western and (c) eastern subpopulations separately

Table 2. Eubalaena japonica. Performance measures (gain and AUC [area under the receiver-operating characteristic curve]) for the different models generated for the present analysis. Annual models were built at basin extents for 3 subsets of the observational data (Obs.: all, western [W] and eastern [E] subpopulations) and at reduced (regional) spatial extents for the subpopulation models only. Seasonal (spring and summer) models were produced at basin extents using W and E dependent data and a subset of the W subpopulation data (W-s) that excluded potentially non-foraging right whales. Performance measures were calculated using the full set of observations available at each spatial and temporal scale. The number of predictors used (Pred.) is shown for each group of models

\begin{tabular}{|c|c|c|c|c|c|c|}
\hline Annual models & Pred. & Obs. & $\begin{array}{c}\text { Performan } \\
\text { Gain }\end{array}$ & $\begin{array}{l}\text { measures } \\
\text { AUC }\end{array}$ & & \\
\hline Basin-extent, full & 19 & All & 1.317 & 0.937 & & \\
\hline Basin-extent, subpopulation & & W & 1.964 & 0.967 & & \\
\hline Basin-extent, subpopulation & & $\mathrm{E}$ & 2.148 & 0.977 & & \\
\hline Regional, subpopulation & & $\mathrm{W}$ & 0.647 & 0.817 & & \\
\hline Regional, subpopulation & & $\mathrm{E}$ & 1.264 & 0.901 & & \\
\hline Basin-extent, reduced, full & 12 & All & 1.246 & 0.926 & & \\
\hline Basin-extent, reduced, subpopulation & & W & 1.904 & 0.966 & & \\
\hline Basin-extent, reduced, subpopulation & & $\mathrm{E}$ & 2.084 & 0.974 & & \\
\hline \multirow{2}{*}{$\begin{array}{l}\text { Seasonal subpopulation models } \\
\text { (basin extents) }\end{array}$} & & & \multicolumn{2}{|c|}{ - Spring — } & \multicolumn{2}{|c|}{ - Summer } \\
\hline & & & Gain & AUC & Gain & AUC \\
\hline \multirow[t]{3}{*}{ Seasonal, reduced annual } & 12 & $\mathrm{~W}$ & 2.186 & 0.970 & 2.268 & 0.976 \\
\hline & & $\mathrm{W}-\mathrm{s}$ & 2.659 & 0.980 & 2.712 & 0.984 \\
\hline & & E & 2.372 & 0.979 & 2.313 & 0.975 \\
\hline \multirow[t]{2}{*}{ Annual + seasonal } & 20 & W-s & 2.816 & 0.984 & 2.769 & 0.986 \\
\hline & & $\mathrm{E}$ & 2.463 & 0.981 & 2.582 & 0.983 \\
\hline \multirow[t]{2}{*}{ Reduced seasonal } & $9-12$ & W-s & 2.723 & 0.981 & 2.730 & 0.985 \\
\hline & & $\mathrm{E}$ & 2.398 & 0.980 & 2.566 & 0.982 \\
\hline
\end{tabular}


Table 3. Eubalaena japonica. Results of data scaling experiments: Reference values are for models prior to re-scaling; scaled values are for models using subsets of the dependent data; $95 \%$ confidence intervals are for the null model used to assess the significance of the change in performance between the reference and scaled models, as measured by Gain and AUC (area under the receiver-operating characteristic curve). Results are for 3 experiments: Full, annual to subpopulation (west, east); annual to seasonal (spring, summer) by subpopulation (western, eastern); and biased data removal for the western subpopulation only. See 'Materials and methods' for details

\begin{tabular}{|c|c|c|c|c|c|c|c|c|}
\hline & \multirow{2}{*}{\multicolumn{2}{|c|}{$\overline{\text { Scale to subpopulations }}$}} & \multicolumn{4}{|c|}{ Western subpopulation } & \multirow{2}{*}{\multicolumn{2}{|c|}{$\begin{array}{l}\text { Eastern subpopulation } \\
\text { Scale to seasons }\end{array}$}} \\
\hline & & & \multicolumn{2}{|c|}{ Scale to seasons } & \multicolumn{2}{|c|}{ Biased data removed } & & \\
\hline & West & East & Spring & Summer & Spring & Summer & Spring & Summer \\
\hline \multicolumn{9}{|l|}{ Gain } \\
\hline Reference & \multicolumn{2}{|c|}{1.317} & \multicolumn{2}{|c|}{1.904} & 2.186 & 2.268 & \multicolumn{2}{|c|}{2.084} \\
\hline Scaled & 1.964 & 2.148 & 2.186 & 2.268 & 2.659 & 2.712 & 2.372 & 2.313 \\
\hline \multirow[t]{2}{*}{$95 \%$ CI } & 1.4886 & 1.4795 & 2.0477 & 2.0997 & 2.2872 & 2.3179 & 2.2022 & 2.2804 \\
\hline & 1.4863 & 1.4817 & 2.0508 & 2.1040 & 2.2985 & 2.3233 & 2.2079 & 2.2847 \\
\hline \multicolumn{9}{|l|}{ AUC } \\
\hline Reference & \multicolumn{2}{|c|}{0.937} & \multicolumn{2}{|c|}{0.966} & 0.970 & 0.976 & \multicolumn{2}{|c|}{0.974} \\
\hline Scaled & 0.967 & 0.977 & 0.970 & 0.976 & 0.980 & 0.984 & 0.979 & 0.975 \\
\hline \multirow[t]{2}{*}{$95 \% \mathrm{CI}$} & 0.9379 & 0.9378 & 0.9642 & 0.9658 & 0.9713 & 0.9736 & 0.9714 & 0.9747 \\
\hline & 0.9381 & 0.9380 & 0.9643 & 0.9660 & 0.9717 & 0.9738 & 0.9716 & 0.9748 \\
\hline
\end{tabular}

ables in the eastern spring and summer models, respectively, with only a marginal drop in performance (Tables $2 \& 4$ ).

The mean gain as a function of redundant variables removed did not follow a monotonic distribution (Fig. 4). I therefore selected the model with the least number of variables whose gain was within the confidence interval of the fully specified model, and preceded all subsequent models with mean gain below this threshold. To ensure that the observed fluctuation on model performance was not due to the subsampling used for the jackknife procedure, I calculated the gain for the full sample of dependent data for both subpopulations, in spring, to compare with the randomised results (Fig. 4).

Similar to the annual models, the reduced seasonal subpopulation models were dominated by $t_{10}$, although more so in spring than summer (Table 1). In spring, the western subpopulation model included contributions $>10 \%$ from surface mixing $\left(\Delta t_{1}\right)$ and $z_{\text {, }}$ while, in the east, $d_{\mathrm{uw}}$ and annual variability in surface temperature $\left(\mathrm{av}_{t, \text { surf }}\right)$ were the other significant contributors. In summer, in the west, $t_{10}$ was reduced in importance, while the contribution of $\Delta t_{1}$ almost doubled and $d_{\mathrm{uw}}$ replaced $z$ as the third most significant contributor. In the east, similar variables contributed in both spring and summer, but summer showed increased contributions from annual variability in both surface salinity and temperature $\left(\mathrm{av}_{s, \text { surf }}\right.$ and $\left.\mathrm{av}_{t, \mathrm{surf}}\right)$ (Table 1).

The seasonal models (Fig. 5) showed habitat predictions of high suitability moving from offshore areas in spring to on-shelf areas in summer, although this was more evident for the western subpopulation.
The reduced spring model predicted areas of high suitability offshore in the west, while, in the east, high suitability predictions were concentrated offshore of Kodiak Island and in the northern GOA. The summer model in the west showed areas of high predicted suitability extending from the shelf waters

Table 4. Predictor variables in order of decreasing redundancy for subpopulation models, by season. Redundancy was defined as how readily the variable's contribution to the model could be replaced by the remaining variables. The shaded variables were retained in the seasonal reduced models. See Table 1 for variable codes and 'Materials and methods' for details

\begin{tabular}{|c|c|c|c|}
\hline \multicolumn{2}{|c|}{ Western } & \multicolumn{2}{|c|}{ Eastern } \\
\hline Spring & Summer & Spring & Summer \\
\hline$\Delta t_{2}$ & $S_{\text {bot }}$ & $S_{\text {bot }}$ & $S_{\text {bot }}$ \\
\hline $\mathrm{Sv}_{S_{,} \text {surf }}$ & $\mathrm{SV}_{S, \text { bot }}$ & $\Delta s_{2}$ & $\Delta s_{2}$ \\
\hline$S_{\text {bot }}$ & $\Delta s_{2}$ & $d_{200}$ & $\Delta t_{2}$ \\
\hline $\operatorname{vel}_{150}$ & $\operatorname{vel}_{150}$ & $\mathrm{sv}_{t, \mathrm{bot}}$ & $\mathrm{sv}_{t, \text { bot }}$ \\
\hline$\Delta s_{2}$ & $\mathrm{av}_{S, \text { bot }}$ & $\mathrm{av}_{s, \mathrm{bot}}$ & $\mathrm{av}_{s, \mathrm{bot}}$ \\
\hline $\mathrm{av}_{s, \text { bot }}$ & $\mathrm{SV}_{t, \text { bot }}$ & $\mathrm{SV}_{t, \mathrm{bot}}$ & $d_{200}$ \\
\hline $\mathrm{av}_{t_{t} \text { surf }}$ & $\mathrm{av}_{s, \text { surf }}$ & $S_{10}$ & $w$ \\
\hline $\mathrm{sv}_{t, \text { surf }}$ & $\mathrm{sv}_{t, \text { surf }}$ & $\Delta t_{1}$ & $\mathrm{av}_{t, \mathrm{bot}}$ \\
\hline $\mathrm{sv}_{t, \text { bot }}$ & $W$ & $\mathrm{av}_{t, \text { surf }}$ & $z$ \\
\hline $\mathrm{av}_{S, \text { surf }}$ & vel $_{\text {surf }}$ & $\mathrm{vel}_{\text {surf }}$ & $\mathrm{SV}_{s, \text { bot }}$ \\
\hline $\mathrm{SV}_{S, \text { bot }}$ & $\Delta t_{2}$ & $\mathrm{av}_{S, \text { surf }}$ & vel $_{\text {surf }}$ \\
\hline vel $_{\text {surf }}$ & $\mathrm{Sv}_{S, \text { surf }}$ & $\mathrm{SV}_{S, \text { surf }}$ & $d_{\mathrm{u} w}$ \\
\hline$w$ & $\mathrm{av}_{t, \text { surf }}$ & $\mathrm{av}_{s, \mathrm{bot}}$ & $\mathrm{SV}_{S, \text { surf }}$ \\
\hline$\Delta t_{1}$ & $S_{10}$ & $\operatorname{vel}_{150}$ & $\operatorname{vel}_{150}$ \\
\hline$z$ & $z$ & $\mathrm{~Sv}_{t, \text { surf }}$ & $\mathrm{Sv}_{t, \text { surf }}$ \\
\hline$d_{\mathrm{uw}}$ & $t_{10}$ & $w$ & $s_{10}$ \\
\hline$d_{200}$ & $d_{200}$ & $d_{\mathrm{uw}}$ & $\mathrm{av}_{t, \text { surf }}$ \\
\hline$s_{10}$ & $\mathrm{av}_{t, \text { bot }}$ & $t_{10}$ & $t_{10}$ \\
\hline$t_{10}$ & $d_{\mathrm{uw}}$ & $\Delta t_{2}$ & $\Delta t_{1}$ \\
\hline $\mathrm{av}_{S, \text { bot }}$ & $\Delta t_{1}$ & $z$ & $\mathrm{av}_{\mathrm{S}, \mathrm{surf}}$ \\
\hline
\end{tabular}




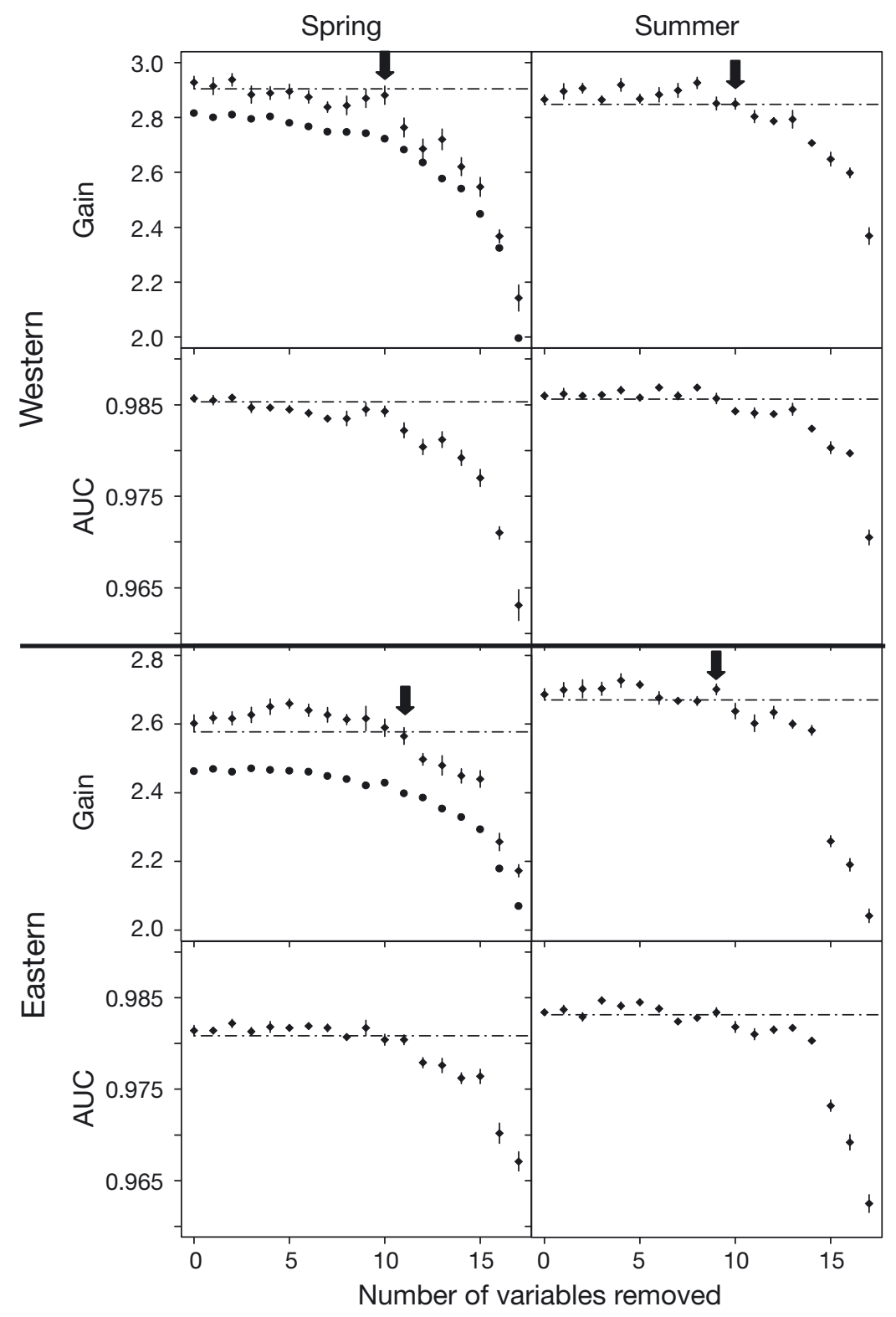

Fig. 4. Eubalaena japonica. Redundancy plots showing how performance measures (gain and AUC [area under the receiver-operating characteristic curve]) responded to the removal of predictor variables according to their redundancy in the seasonal subpopulation models. Black arrows indicate the partial model just before the gain dropped permanently below the confidence interval of the fully specified model. Spring plots show gain for both subsampled (with 95\% confidence intervals) and full models (no confidence intervals), indicating that randomisation of the subsample was not responsible for the non-monotonic reduction in gain

northeast of Hokkaido to the western side of the Kamchatka peninsula, as well as some patches of predicted high suitability on the eastern side of Kamchatka. The eastern summer model showed high suitability in the northern GOA, particularly between the Queen Charlotte Islands (QCI) in British Colum- bia and Prince William Sound, Alaska. Higher suitability predictions also extended south towards the central GOA. High suitability was also predicted on the SEBS shelf.

I found several significant differences between where right whales were killed and the background (i.e. average) ocean conditions and between the average conditions occupied by the 2 subpopulations (Fig. 6). For both subpopulations, kills occurred in surface waters $\left(t_{10}\right)$ considerably colder on average than background and with a much narrower distribution of values, particularly for the eastern subpopulation. Animals in the east occupied colder waters than those in the west in both seasons. Annual surface temperature variability $\left(a_{t, \text { surf }}\right)$ differed by subpopulation, with the animals in the east caught in areas of lower $\mathrm{av}_{t, \text { surf }}$, while, in the summer, the bulk of the western animals were caught in areas with higher variability. Seasonally, $\mathbf{s v}_{t, s u r f}$ was higher for occurrences from both subpopulations in both seasons, with spring showing a narrower distribution of variability. Eastern animals occurred closer to canyons than western animals in both spring and summer, with both subpopulations showing a narrower distribution of distances in summer (Fig. 6).

\section{DISCUSSION}

Understanding how an animal perceives its environment and uses environmental cues to find foraging habitat is a central ecological question for all species. For rare, highly mobile species like North Pacific right whales, such an understanding would benefit conservation efforts by helping identify potential impediments to the species' recovery. While we are unlikely to ever understand completely how animal behaviour interacts with habitat characteristics, we nevertheless can - and indeed must - speculate about the processes that may be important at different spatial and temporal scales (e.g. Kenney et al. 2001, Baumgartner et al. 2007). The pre- 


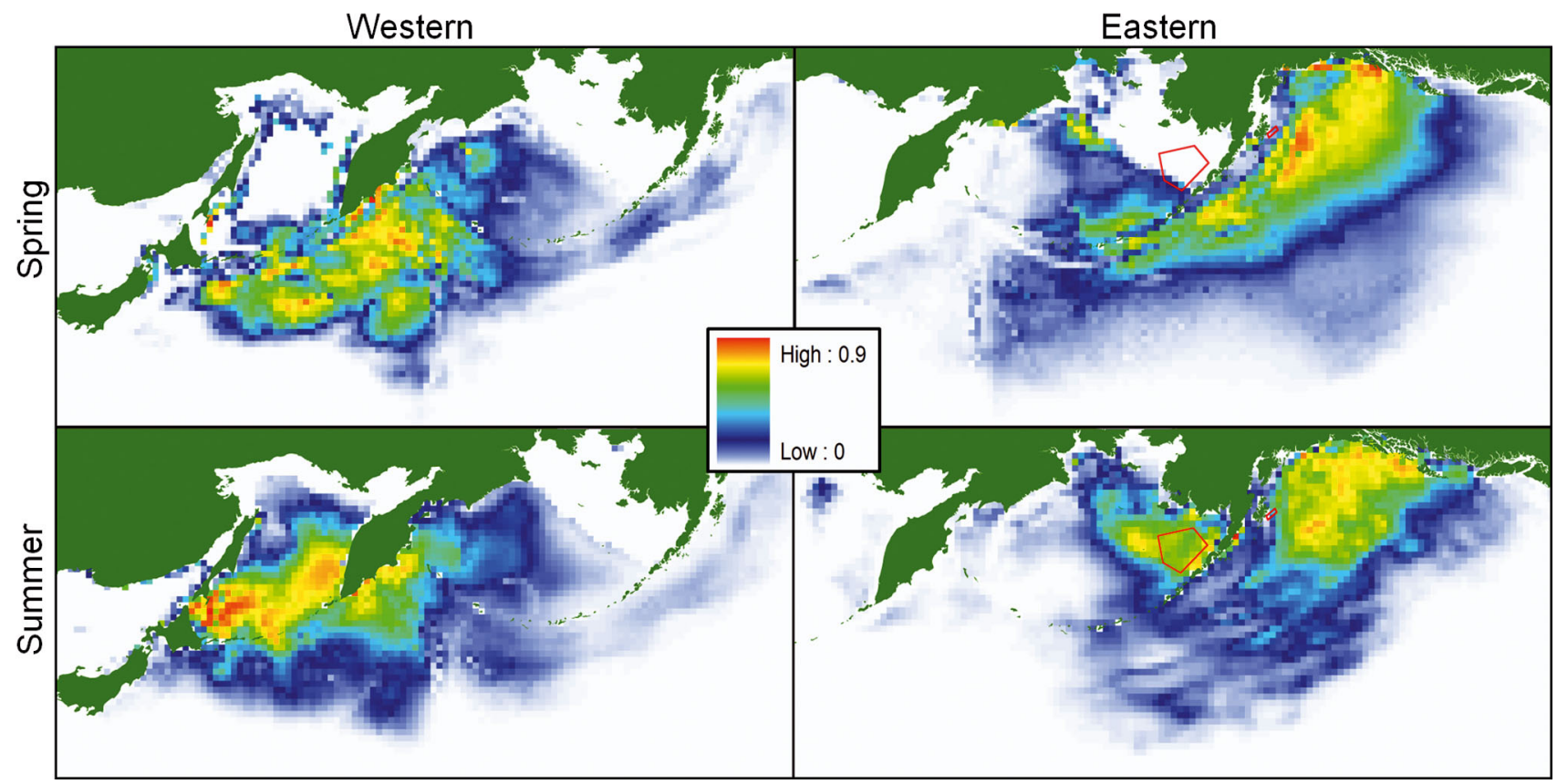

Fig. 5. Eubalaena japonica. Predicted seasonal habitat for the western and eastern subpopulations of North Pacific right whales

sent study contributes to the information available for such reflections by providing the most detailed correlational analysis to date between right whale observations and environmental conditions, at 2 spatial extents and 2 temporal resolutions.

\section{Habitat predictions}

The improved fit of the subpopulation models compared to the annual model lends support to the hypothesis that 2 subpopulations exist in the North Pacific. By their nature, the subpopulation models predict non-overlapping habitats with different oceanographic signatures (Fig. 3, Table 1). Since cetaceans are believed to transfer knowledge of suitable foraging habitat across generations (Rendell \& Whitehead 2001), dispersal to new foraging grounds can be delayed or not occur at all if currently used habitats provide sufficient prey. Since the animals killed on the 2 sides of the North Pacific occupied differentiated habitats, and, assuming that severely reduced population sizes would make dispersal unnecessary, the right whales observed recently on the SEBS are more likely a remnant of the eastern subpopulation than dispersing animals from the west.

The improved fit of the seasonal (spring and summer) over the annual models for both subpopulations emphasises the importance of including seasonal res- olution when modelling migrating species. The shifting of predicted habitats from offshore to on-shelf regions, particularly in the west, supports the hypothesis that right whales make use of foraging habitats in the open ocean in the spring, before moving to foraging areas along the shelf-edge and onshelf later in the season (Gregr \& Coyle 2009).

The seasonal predictions are also supported, again more so in the west, by high correspondence between predicted summer suitability and documented historical whaling areas. The area along the shelf edge, about halfway from Hokkaido to Kamchatka, was a known hotspot for right whales (Reeves et al. 2008) and is one of 3 highly productive upwelling areas in the Sea of Okhotsk (Ivashchenko \& Clapham 2010). The predicted foraging area off the west coast of Kamchatka corresponds closely to the coordinates given $\left(53^{\circ} 02^{\prime} \mathrm{N}, 152^{\circ} 30^{\prime} \mathrm{E}\right)$ for the Midas Ground - also a historic right whale whaling ground (Reeves et al. 2008), while the area between Sakhalin Island and Hokkaido is a natural bottleneck leading from the Sea of Japan to the Sea of Okhotsk. These last 2 areas are also where the major Sea of Okhotsk currents interact with bottom topography to create potential vertical mixing and entraining frontal structures. These 3 habitats are much less resolved by the annual model.

In the east, there is little information with which to evaluate the predicted change in seasonal habitat. 

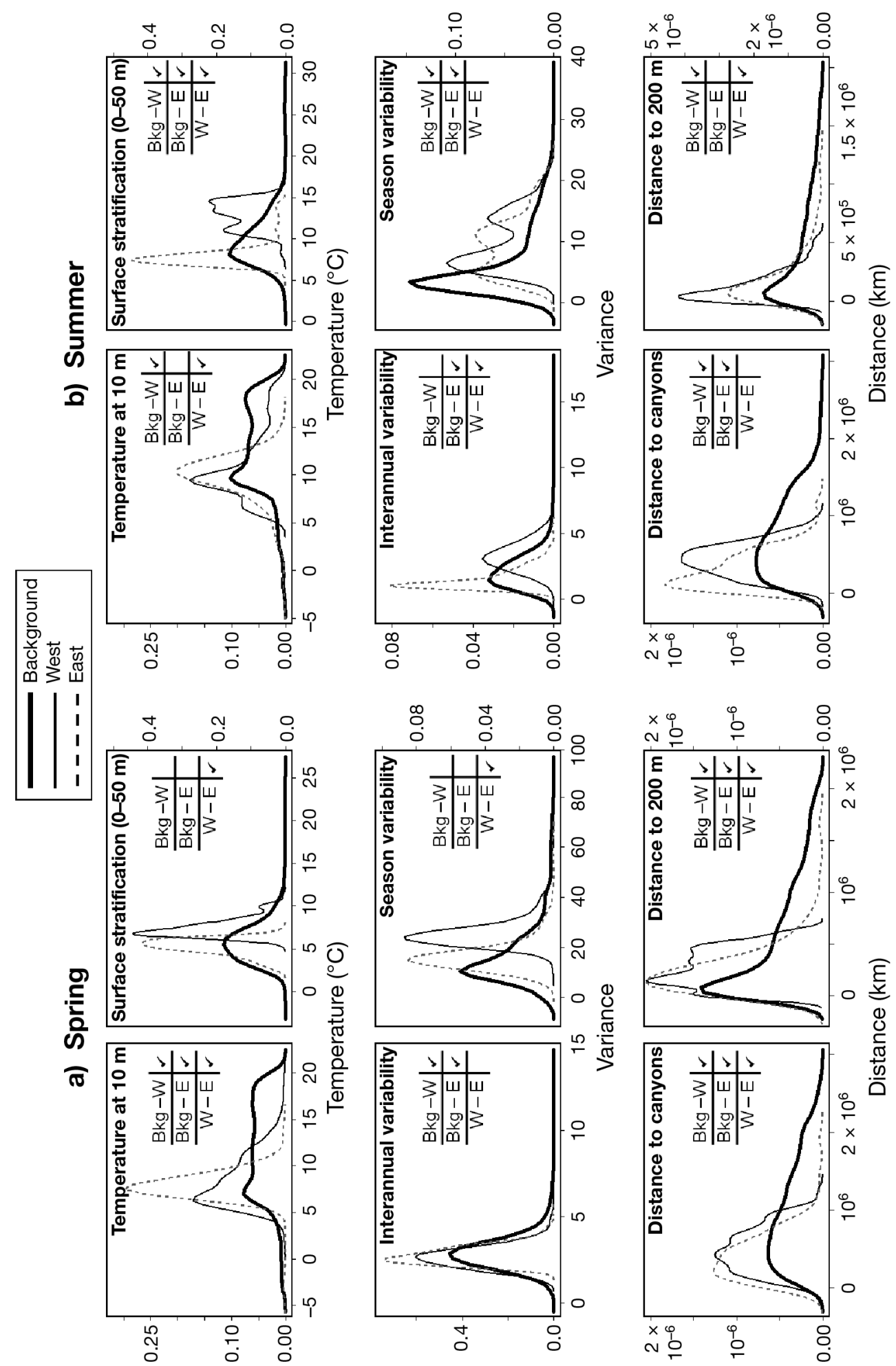

Density (proportion of total cells)

Fig. 6. Eubalaena japonica. Density plots comparing temperature, interannual and seasonal variability in surface temperature, and geographic distances between locations where right whales from the western (solid line, grey) and eastern (dashed line) subpopulations were killed compared to the oceanic background (heavy black line) in areas where temperature at $10 \mathrm{~m}$ depth was $<20^{\circ} \mathrm{C}$ in (a) spring and (b) summer. Table insets indicate significant differences $(\alpha=0.05$; check mark) between background $(\mathrm{Bkg})$ and western (W), Bkg and eastern (E), and W and E data based on Kolmogorov-Smirnov tests of equal distributions 
However, of the few dozen right whale sightings on the SEBS since 1982, the majority have occurred in July, with a single sighting reported earlier (June) and a handful later, in August and September (Shelden et al. 2005). This supports the prediction that the SEBS is more of a summer (July to September) rather than spring habitat. Recent acoustic and tagging data show that right whales continue to occupy this habitat until as late as December (Phil Clapham pers. comm.).

The spring models provide an intriguing picture of potential oceanic habitats on both sides of the basin, corresponding reasonably well to areas where mesoscale eddies, cross-shelf transport currents and the interaction between the large-scale ocean currents are believed to generate right whale habitat features (Gregr \& Coyle 2009). Such features create discontinuities in average ocean conditions and can be characterised by areas with low surface temperatures (e.g. Etnoyer et al. 2004) or high seasonal variability, as described here. In the west, predicted areas of high spring suitability are small and patchy, suggesting less temporal persistence in the major currents in the region, while, in the east, predicted oceanic habitat patches occur where strong oceanic currents may interact with buoyancy-driven coastal currents (Gregr \& Coyle 2009).

The summer prediction for the eastern subpopulation shows a swath of high predicted habitat suitability extending from QCI to the central GOA. This area corresponds with a path often taken by meso-scale eddies generated along the eastern GOA shelf (Crawford et al. 2007, Gregr \& Coyle 2009). Another line of predicted high suitability extending from QCI to Prince William Sound follows both an area of high eddy energy (Ladd 2007) and a seamount chain, making it a region with considerable potential for current-topography interactions. If the right whale's migratory path includes this region of the GOA, it is possible that sufficient prey are encountered in some years to make the full migration to the SEBS unnecessary (Gregr \& Coyle 2009). This could explain why right whales have not been encountered on the SEBS in all years.

\section{Habitat characterisation}

Despite little spatial overlap, the annual subpopulation habitat predictions (Fig. 3) were both dominated by $d_{\mathrm{uw}}$ and $t_{10}$. The importance of temperature was emphasised at the seasonal resolution, where $t_{10}$ persisted as the dominant predictor for both subpop- ulations. Although the contribution of the geographic predictors was overshadowed by the ocean climate variables, the distance variables $\left(d_{200}\right.$ and $\left.d_{\mathrm{uw}}\right)$ nevertheless provided notable contributions. In the west, $d_{200}$ contributed in both seasons, while $d_{\text {uw }}$ was important in summer when its contribution was plainly evident in the area of predicted high suitability centred on the canyons east of Hokkaido. In the east, $d_{\mathrm{uw}}$ contributed to the models in both seasons and can be attributed to the canyons identified around the northern GOA (Fig. 1).

The addition of relevant ocean climate at the seasonal resolution is the likely cause of the reduced contribution by geographic variables at the seasonal scale (compare annual and seasonal columns in Table 1). While such changes in model specification can lead to improvements in model performance, changes in the dependent data can have a similar effect. For example, dividing the dependent data into subpopulations resulted in a large improvement in model performance over the model using all the dependent data (Table 3), lending support to the separation of subpopulations. Similarly, applying the variables from the reduced annual models at the seasonal resolution again improved model performance, suggesting that the dependent data were better described at a seasonal resolution. This method of iterative model development allows hypotheses about species ecology and data quality to be tested.

Removing the records for presumably non-foraging right whales from the western subpopulation model is another example of such testing. The removal of these data improved model performance and generated more interpretable predictions. Understanding such biases in opportunistically collected presence data is essential for accurate interpretation of habitat models (Lozier et al. 2009). While such experiments are by no means definitive, they help challenge the assumptions we hold about our data and our study system.

Notable for its lack of contribution to the models was current velocity. The currents at different depths were highly cross-correlated, leaving only the surface and $150 \mathrm{~m}$ velocities in the annual model. Forcing winds also remained in the model, providing a temporal lag to the slower, ocean processes, and ultimately had the largest contribution from this set of predictors, ranking fifth in a single seasonal model. However, the contribution from surface currents and wind speed increased at the regional scale (Table 1). This suggests that these forces are more directly relevant at reduced extents and finer resolution, while their role at the basin scale is captured by more integrative predictors such as temperature. 
The seasonal subpopulation habitats were characterised largely by $t_{10}$ and $\Delta t_{1}$ (in the west), with significant contributions from the distance variables. Additionally, annual and seasonal surface temperature variability contributed notably in the east. This led me to investigate the role of temperature in more detail by examining how the temperature variables compared between where the whales were killed and the average ocean conditions (Fig. 6). In all cases, the suite of temperature variables was notably, and sometimes dramatically, different from background. These differences can be partially explained by the species' northern distribution, but this cannot explain the differences observed in inter-annual and within-season variability. Rather, they are likely also a function of the whales' distribution along the shelf edge, where colder waters can be expected on average due to upwelling. The variability indices provide additional clues about how right whales respond to their environment.

As a measure of year-to-year predictability, lower values of $\mathrm{av}_{t}$ imply a higher likelihood of an area having similar year-to-year seasonal temperatures. Thus, the association of right whales with lower surface $\mathrm{av}_{t}$ in spring, coupled with lower temperatures and an offshore distribution may be an indication of predictable surface mixing and, given the large contribution from $d_{\mathrm{uw}}$ in the east, an indication of canyonderived upwelling. Since these areas would be more likely to support spring concentrations of oceanic copepods (Gregr \& Coyle 2009), experience with where such features occur predictably would enhance the foraging success of right whales.

The summer differences in surface $\mathrm{av}_{t}$ between the subpopulations (Fig. 6b) reflect the difference between predicted suitability in the west which occurred in the more dynamic shelf ecosystem, and that in the east, where the central GOA appears to represent a region of fairly constant year-to-year temperatures.

Seasonal surface temperature variability $\left(\mathrm{sv}_{t}\right)$ in spring was much higher than background ocean conditions for kills from both subpopulations (Fig. 6a). If high short-term variability in temperature can be interpreted as an indication of high frontal activity (Gregr \& Trites 2008), then these animals would have been in areas with a higher frequency of ephemeral fronts, an indicator of potential prey concentrations (Hyrenbach et al. 2000, Gregr \& Coyle 2009). While these variance measures ranked in the top 5 in the east, they were not retained in the western subpopulation model, possibly because of correlated predictors (especially $t_{10}$ and $\Delta t_{1}$ ) capturing other aspects of the same process.
Taken together, the association of right whales with cold waters, low inter-annual variability and high within-season variability supports the notion that these animals frequent areas where high frontal activity occurs predictably every year. This appears true for both spring oceanic habitats and on-shelf summer habitats, though the physical signals are subtly different. The importance of temperature at large spatial scales has also been related to right whale life history, with Southern Ocean calving rates correlated with inter-annual sea surface temperature anomalies (Leaper et al. 2006). Understanding how such oceanic habitats re-occur is central to efforts to identify and protect regions of biological importance.

\section{Scaling, assumptions, and model performance}

It is unlikely that the same predictor variables will have a consistent relationship with right whale habitat across all scales. It is therefore worth considering how the persistence of key predictor variables changed across scales, providing insight into the underlying processes. For example, the contribution from $t_{10}$ was high at annual and seasonal resolutions at the basin scale, but not at reduced spatial extents, where variables such as surface winds and $d_{200}$, among others, provided increased contributions (Table 1). This implies that temperature (possibly reflecting deep-water influences) is an important indicator at basin extents, but becomes less reliable at regional extents where more dynamic or more proximate (sensu Austin 2002) variables characterise local processes. Similarly $d_{\mathrm{uw}}$ was also important at the annual and seasonal scales, but not at regional extents, suggesting that any putative influence of canyons would be better resolved at the regional scale by more than just distance.

At any scale of analysis, it is also important to consider underlying assumptions. The most important assumption here is that a 50 yr climatology from the 20th century can describe the relative environmental conditions during the brief (1840 to 1850) period of intense right whale exploitation at the end of the little ice age (ca. 1350 to 1900). I argue that since longterm processes are expressed over large spatial extents (Wiens 1989), the ecological relevance of these climatologies is at the basin-scale, where features of importance will be largely defined by the interaction of major oceanic currents with each other and with the bathymetry (Gregr \& Coyle 2009). Thus, my use of long-term climatologies mitigated any dif- 
ferences between the 2 eras and retained only the strong, persistent, seasonal signals in the data.

This underlying assumption is consistent with available data. Temperatures reconstructed from tree ring data show that while from 1850 to 1865 summer air temperatures were low, comparable cold periods occurred in the early 1900s and 1970s (Mann et al. 1998). Perhaps more importantly, the same time series shows periods from 1750 through 1900 with temperatures similar to the 20th century. Additionally, the Pacific Decadal Oscillation, which has a strong influence on weather patterns in the North Pacific, was actually in a cooler phase from 1950 to 1976 than during the right whale whaling era (Biondi et al. 2001). Finally, whaling occurred in the Bering Sea in summer throughout the 1840s (Josephson et al. 2008b), and accounts from Arctic logbooks contain no indication of unusually cold conditions (Wood \& Overland 2003). Thus, while an overall warming trend in air temperature is evident in the region (Moore et al. 2002), there is little to suggest that the ocean climate in the North Pacific during the mid19 th century was in any way dramatically different from the 20th century.

As with all distributional analyses of opportunistic data, the present study assumed that the Townsend data provided an accurate and unbiased representation of the distribution of foraging right whales in the North Pacific. The catch data are likely biased to some degree due to the uneven distribution of whaling effort. However, because this bias was primarily towards favourable habitat (e.g. whalers concentrated on known whaling grounds), and because whaling was an opportunistic endeavour (i.e. whales were hunted when encountered), any bias will be towards preferred whale habitat, making the resulting model predictions conservative rather than inaccurate. Despite potential transcription errors from original sources (Josephson et al. 2008b), such data represent valuable information on the historic distribution of exploited species. The data removal experiments conducted here showed how the removal of potentially unreliable data can improve model performance and thus provide one approach to exploring questions of correct transcription. Additionally, while there is no information on the positional accuracy of the log book records (Wildlife Conservation Society 2004), the use of large grid cells and basinscale extents minimised the influence of any such inaccuracies.

All told, this work has generated reasonable hypotheses about how topography and long-term averages of ocean climate might explain the basin- scale distribution of right whale foraging habitat. As habitat predictions at the broadest spatio-temporal scale, they provide a context, or a type of boundary condition, suitable for refinement with higher resolution studies (Gregr \& Coyle 2009).

\section{Future efforts}

First and foremost, efforts to collect contemporary observations and conduct tagging studies should continue, as these data are necessary to answer key ecological questions about right whale habitat use. Such efforts can be informed by predictive models such as those presented here.

In the eastern north Pacific, the summer habitat predictions partially correspond with the legally designated 'critical habitat' on the SEBS shelf under the United States Endangered Species Act (Clapham et al. 2005). However, there was little correspondence with the critical habitat off Kodiak Island in either seasonal model (Fig. 5). Enhanced acoustic detection efforts in the northern GOA in both shelf-edge and oceanic ecosystems would help determine the degree to which right whales continue to use this area and whether changes to the existing critical habitat designation in the GOA are warranted.

Regional models with higher spatial and temporal resolution using concurrent sighting and predictor data will help refine the oceanic habitats and support investigations of the processes hypothesised here. Such efforts will also help describe the influence of potential predictor variables at different scales, improving our understanding of how ocean climate creates suitable foraging habitat for the North Pacific right whale.

\section{CONCLUSIONS}

The habitat predictions presented demonstrate a number of basin-scale patterns that improve our understanding of right whale stock structure and distribution, help characterise right whale foraging habitat and provide some explanation of the seasonal movements between potential foraging areas. By describing the distribution and characteristics of persistent suitable foraging habitats, the models provide insights into ocean features potentially used by right whales to locate suitable foraging habitats today.

The existence of 2 subpopulations is supported by habitat predictions that are spatially separated, with different ecological signatures. These habitat differ- 
ences are characterised both by the inclusion of different predictor variables and by the differences in contributions by similar predictor variables. This suggests that the 2 subpopulations are specialised to the different oceanic conditions that provide suitable foraging areas on the 2 sides of the North Pacific basin. Thus, the animals seen in the last $20 \mathrm{yr}$ on the SEBS are likely remnants of a distinct eastern stock, rather than dispersers from the more numerous western North Pacific population.

Predicted habitats in the western North Pacific correspond to known historic whaling grounds, while, in the east, a known present-day summer habitat on the SEBS shelf is represented. The habitat predicted in the GOA, while plausible, remains to be validated as a present-day foraging habitat. Such validation could be accomplished by expanding the use of remote acoustic hydrophones in the region.

High habitat suitability was predicted by all the seasonal subpopulation models in areas where longterm ocean conditions could be reasonably expected to create enrichment and retention features at seasonal and basin scales. Indicators of potential habitat at this broad scale would provide right whales with an idea of where to search for foraging patches at different times of the year. The location of actual habitat patches at finer spatial resolutions and at more specific times of the year will depend on how local, more immediate processes modify the longer term, broader scale patterns.

Acknowledgements. This project could not have been completed without the moral support and guidance of Bob Brownell, Phil Clapham and Randy Reeves. Kim Shelden provided data and advice, Kevin Wood provided helpful discussion on the state of the North Pacific during the mid-1900s. Yi Chao and Carrie Hongchun Zhang assembled the considerable output from their circulation model, which Rowenna Gryba compiled into the annual and seasonal climatologies. Detailed reviews by R. Reeves and Cathryn Clarke-Murray, and the second pair of eyes provided by R. Gryba, greatly improved the quality of the manuscript. This article is North Pacific Research Board publication 310, from Project 633.

\section{LITERATURE CITED}

Amante C, Eakins BW (2009) ETOPO1 1 arc-minute global relief model: procedures, data sources and analysis. Technical Memorandum NESDIS NGDC-24, NOAA, Boulder, CO, p 19

Austin MP (2002) Spatial prediction of species distribution: an interface between ecological theory and statistical modelling. Ecol Modell 157:101-118

Bakun A (1996) Patterns in the ocean: ocean processes and marine population dynamics. California Sea Grant College System, La Jolla, CA
Baumgartner MF, Mayo CA, Kenney RD (2007) Enormous carnivores, microscopic food, and a restaurant that's hard to find. In: Kraus SD, Rolland RM (eds) The urban whale. North Atlantic right whales at the crossroads. Harvard University Press, Cambridge, MA, p 138-171

Biondi F, Gershunov A, Cayan DR (2001) North Pacific decadal climate variability since 1661 . J Clim 14:5-10

Braham HW, Rice DW (1984) The right whale, Balaena glacialis. Mar Fish Rev 46:38-44

Brownell RL Jr, Clapham PJ, Miyashita T, Kasuya T (2001) Conservation status of North Pacific right whales. J Cetacean Res Manag 2(Special Issue):269-286

Clapham PJ, Good C, Quinn SE, Reeves RR, Scarff JE, Brownell RL Jr (2004) Distribution of North Pacific right whales (Eubalaena japonica) as shown by 19th and 20th century whaling catch and sighting records. J Cetacean Res Manag 6:1-6

Clapham P, Shelden K, Wade P (2005) Review of information relating to possible critical habitat for eastern North Pacific right whales. NMML, NMFS, Seattle, WA

Crawford WR, Brickley PJ, Thomas AC (2007) Mesoscale eddies determine phytoplankton distribution in northern Gulf of Alaska. Prog Oceanogr 75:287-303

Dudík M, Phillips SJ, Schapire RE (2007) Maximum entropy density estimation with generalized regularization and an application to species distribution modeling. J Mach Learn Res 8:1217-1260

- Elith J, Graham CH (2009) Do they? How do they? Why do they differ? On finding reasons for differing performances of species distribution models. Ecography 32: 66-77

Elith J, Graham CH, Anderson RP, Dudík M and others (2006) Novel methods improve prediction of species' distributions from occurrence data. Ecography 29:129-151

Elith J, Phillips SJ, Hastie T, Dudík M, Chee YE, Yates CJ (2011) A statistical explanation of MaxEnt for ecologists. Divers Distrib 17:43-57

ESRI (Environmental Systems Research Institute) (2008) ArcGIS 9.3. ESRI, Redlands, CA

Etnoyer P, Canny D, Mate B, Morgan L (2004) Persistent pelagic habitats in the Baja California to Bering Sea (B2B) Ecoregion. Oceanography (Wash DC) 17:90-101

$>$ Fielding $\mathrm{AH}$, Bell JF (1997) A review of methods for the assessment of prediction errors in conservation presence/absence models. Environ Conserv 24:38-49

Gregr EJ, Coyle KO (2009) The biogeography of the North Pacific right whale (Eubalaena japonica). Prog Oceanogr 80:188-198

Gregr EJ, Trites AW (2008) A novel presence-only validation technique for improved Steller sea lion Eumetopias jubatus critical habitat descriptions. Mar Ecol Prog Ser 365: 247-261

> Guisan A, Zimmermann NE (2000) Predictive habitat distribution models in ecology. Ecol Modell 135:147-186

> Hyrenbach KD, Forney KA, Dayton PK (2000) Marine protected areas and ocean basin management. Aquat Conserv 10:437-458

> Ivashchenko J, Clapham P (2010) Bowhead whales, Balaena mysticetus, in the Okhotsk Sea. Mammal Rev 40:65-89

Josephson EA, Smith TD, Reeves RR (2008a) Depletion within a decade: the American 19th-century North Pacific right whale fishery. In: Starkey DJ, Holm P, Barnard M (eds) Oceans past: management insights from the history of marine animal populations. Earthscan, London, p 133-147 
Josephson E, Smith TD, Reeves RR (2008b) Historical distribution of right whales in the North Pacific. Fish Fish 9: 155-168

Kenney RD, Mayo CA, Winn HE (2001) Migration and foraging strategies at varying spatial scales in western North Atlantic right whales: a review of hypotheses. J Cetacean Res Manag 2:251-260

Ladd C (2007) Interannual variability of the Gulf of Alaska eddy field. Geophys Res Lett 34:L11605. doi:10.1029/ 2007GL029478

Leaper R, Cooke J, Trathan P, Reid K, Rowntree V, Payne R (2006) Global climate drives southern right whale (Eubalaena australis) population dynamics. Biol Lett 2: 289-292

Lobo JM, Jiménez-Valverde A, Real R (2008) AUC: a misleading measure of the performance of predictive distribution models. Glob Ecol Biogeogr 17:145-151

Lozier JD, Aniello P, Hickerson MJ (2009) Predicting the distribution of Sasquatch in western North America: anything goes with ecological niche modelling. J Biogeogr 36:1623-1627

Mann DH, Crowell AL, Hamilton TD, Finney BP (1998) Holocene geologic and climatic history around the Gulf of Alaska. Arctic Anthropol 35:112-131

> Moore GWK, Holdsworth G, Alverson K (2002) Climate change in the North Pacific region over the past three centuries. Nature 420:401-403

Munk W 2000. Achievements in physical oceanography. 50 years of ocean discovery: National Science Foundation 1950-2000. National Academy Press, Washington, DC, p 44-50

Omura H, Ohsumi S, Nemoto T, Nasu K, Kasuya T (1969) Black right whales in the North Pacific. Sci Rep Whal Res Inst 21:1-78

Phillips SJ, Dudík M (2008) Modeling of species distributions with Maxent: new extensions and a comprehensive evaluation. Ecography 31:161-175

Phillips SJ, Anderson RP, Schapire RE (2006) Maximum entropy modeling of species geographic distributions. Ecol Modell 190:231-259

Reeves RR, Smith TD, Josephson EA (2008) Observations of western gray whales by ship-based whalers in the 19th century. J Cetacean Res Manag 10:247-256

Rendell L, Whitehead H (2001) Culture in whales and dolphins. Behav Brain Sci 24:309-382

Rykiel EJ Jr (1996) Testing ecological models: the meaning of validation. Ecol Model 90:229-244

Editorial responsibility: Brendan Godley, University of Exeter, Cornwall Campus, UK
S-Plus (2007) S-Plus 8.0. Insightful Corporation, Seattle, WA

Scarff JE (1986) Historic and present distribution of the right whale (Eubalaena glacialis) in the eastern North Pacific south of $50^{\circ} \mathrm{N}$ and east of $180^{\circ} \mathrm{W}$. Rep Int Whal Comm Spec Issue 10:43-63

Scarff JE (1991) Historic distribution and abundance of the right whale (Eubalaena glacialis) in the North Pacific, Bering Sea, Sea of Okhotsk and Sea of Japan from the Maury Whale Charts. Rep Int Whal Comm 41:467-489

Shelden KE, Moore SE, Waite JM, Wade PR, Rugh DJ (2005) Historic and current habitat use by North Pacific right whales Eubalaena japonica in the Bering Sea and Gulf of Alaska. Mammal Rev 35:129-155

Tittensor DP, Baco AR, Brewin PE, Clark MR and others (2009) Predicting global habitat suitability for stony corals on seamounts. J Biogeogr 36:1111-1128

Townsend CH (1935) The distribution of certain whales as shown by logbook records of American whaleships. Zoologica (NY) 19:1-50 + 54 charts

Uda M (1963) Oceanography of the subarctic Pacific Ocean. J Fish Res Board Can 20:119-179

Wade PR, Kennedy A, LeDuc R, Barlow J and others (2010) The world's smallest whale population? Biol Lett doi:10. 1098/rsbl.2010.0477

Wang X, Chao Y (2004) Simulated sea surface salinity variability in the tropical Pacific. Geophys Res Lett 31: L02302

Wiens JA (1989) Spatial scaling in ecology. Funct Ecol 3: 385-397

Wildlife Conservation Society (2004) Historical distribution of northern and southern right whale catches based on North American pelagic whaling vessel log book records dating from 1785 to 1913, Version 1.0. Metadata Wildlife Conservation Society, New York, NY

Wisz MS, Hijmans RJ, Li J, Peterson AT, Graham CH, Guisan A (2008) Effects of sample size on the performance of species distribution models. Divers Distrib 14: 763-773

Wood K, Overland JE (2003) Accounts from 19th-century Canadian Arctic explorers' logs reflect present climate conditions. EOS Trans Am Geophys Union 84:410-412

> Yost AC, Petersen SL, Gregg M, Miller R (2008) Predictive modeling and mapping sage grouse (Centrocercus urophasianus) nesting habitat using maximum entropy and a long-term dataset from southern Oregon. Ecol Inform 3:375-386

Submitted: February 28, 2011; Accepted: September 6, 2011 Proofs received from author(s): November 8, 2011 